\title{
Efficiency Optimization of a Standalone PV System Using Dual-MPPT Control
}

\author{
Florin Dragomir, Otilia Elena Dragomir, Nicolae Olariu, Adrian Oprea
}

\begin{abstract}
The main idea of this paper is to design, develop and implement a two-axis tracking photovoltaic (PV) systems, who follows the maximum power point (MPP) using a programmable circuit XILINX type Complex Programmable Logic Device CPLD and Xilinx ISE software. Thus, photovoltaic system will reach its MPP in relation date and time of the day. The test bed relies on an algorithm integrated in the XILINX who has as inputs: date, location's latitude and longitude, the standard longitude, and the number the positions of the Sun's path. For establish the position of the photovoltaic panel in a time of day value is determined by the following calculations: correction factor of Earth's orbit, the solar declination angle, the equation of time in minutes, eastern time using latitude angle, the number of hours the Sun shines using angle eastern time, time the Sun sets, vectors containing the coordinates of the positions of the Sun (in this case 10 positions) during the day and azimuth angle.
\end{abstract}

Keywords - Renewable sources, PV systems, Solar Tracker, programmable circuit, Complex Programmable Logic Device.

\section{INTRODUCTION}

Renewable energy sources (RES) are getting more and more widespread, mainly due to the fact that they generate energy by keeping the environment clean. Theirs rapid evolution of RES during the last two decades materialised in a lot of RES power systems all over the world. A disadvantage of these power plants is the high cost of the installation. In this respect, the approaches trying to optimise the design of these ones are well wellcome. However, such an effort requires detailed knowledge, e.g. the meteorological data of the site where the

Manuscript received December. 31, 2016. (Write the date on which you submitted your paper for review.) This work was supported by a grant of the Romanian National Authority for Scientific Research, CNDI- UEFISCDI, project code PN-III-P2-2.1-BG-2016-0075.

Florin Dragomir is associate professor to Automation, Computer Science and Electrical Engineering Department, Valahia University of Targoviste, Electrical Engineering, Electronics and Information Technology Faculty, nr. 13, Aleea Sinaia, 130004, Targoviste, ROMANIA (e-mail: drg_florin@yahoo.com).

Otilia Elena Dragomir is associate professor to Automation, Computer Science and Electrical Engineering Department, Valahia University of Targoviste, Electrical Engineering, Electronics and Information Technology Faculty, nr. 13, Aleea Sinaia, 130004, Targoviste, ROMANIA (e-mail: dragomir.otilia@valahia.ro).

Nicolae Olariu is principal research to Energy-enviroment Department, Valahia University of Targoviste, Multidisciplinary Science and Technology Research Institute, nr. 13, Aleea Sinaia, 130004, Targoviste, ROMANIA (e-mail: nicolae.olariu@valahia.ro).

Adrian Oprea is doctoral student to Energy-enviroment Department, Valahia University of Targoviste, Multidisciplinary Science and Technology Research Institute, nr. 13, Aleea Sinaia, 130004, Targoviste, ROMANIA (e-mail: adrian.oprea@valahia.ro). system will be installed and operational results from similar systems, if available. [1] and [2].

A PV tracker system is a solution one of those methods able to increase the PV power generation. Theoretical, a PV tracker system with two-axis, can increase the overall solar energy capture about $45 \%$, compared to a fixed PV module tilted at an angle equal to the local latitude. An one-axis tracking system, the increase is approximately $32 \%$. [3]

Sun path refers to the apparent significant seasonal-andhourly positional changes of the sun (and length of daylight) as the Earth rotates, and orbits around the sun. The relative position of the sun is a major factor in the performance of solar energy systems. Accurate location-specific knowledge of sun path and climatic conditions is essential for economic decisions about solar collector area, orientation, landscaping, summer shading, and the cost-effective use of solar trackers. To gather solar energy effectively, a PV panel should be within about twenty degrees either side of perpendicular to the sun.

\section{SySTEM ARHITECTURE}

Positioning on directions east-west and north-south of a solar panel (that is on a trajectory sun tracking device) is reduced to ordering automatic motor on the two axes of orientation system (Figure 1).

Position of the sun was calculated using formulas to approximate azimuth and elevation angles of the sun.

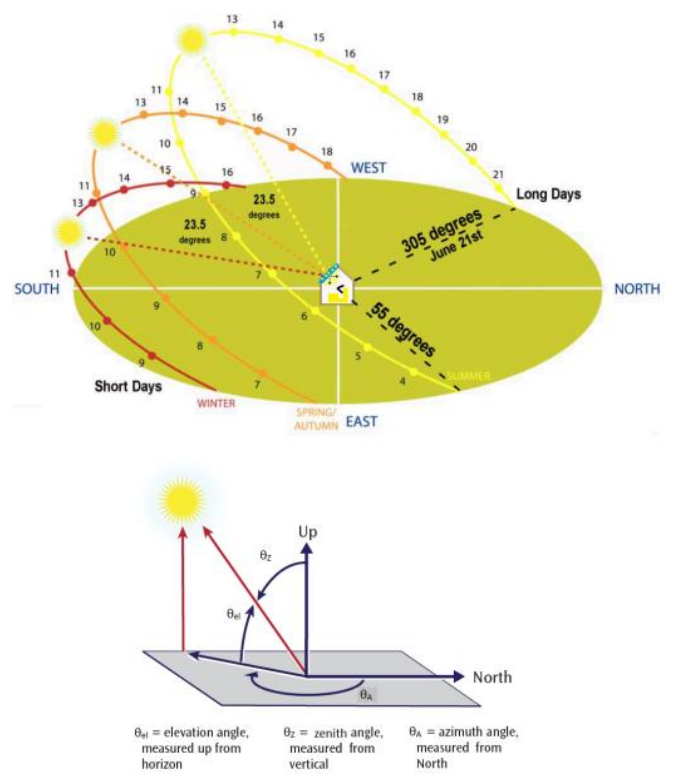

Fig. 1. Elevation angle and azimuth rotation 
To design and develop a prototype positioning for photovoltaic solar panels. Performance conditions are useful table axis transducers to be $25 \mathrm{~kg}$, angular displacement speed up to $2 \mathrm{rev} / \mathrm{min}$ and limit switch heads with hardware method [4].

Mechanical assembly for the vertical axis of rotation of the solar panel complies with kinematics scheme in Figure 2. In order to choose the electric motor you must know the operating conditions (work schedule, temperature and humidity environment), the required power and the rotation speed of the motor shaft. The motor-gearbox chosen to drive the axis is GP232004, manufactured by Baldor enterprise. The engine consumption must be low, and its torque must be multiplied by the mechanical transmissions [5].

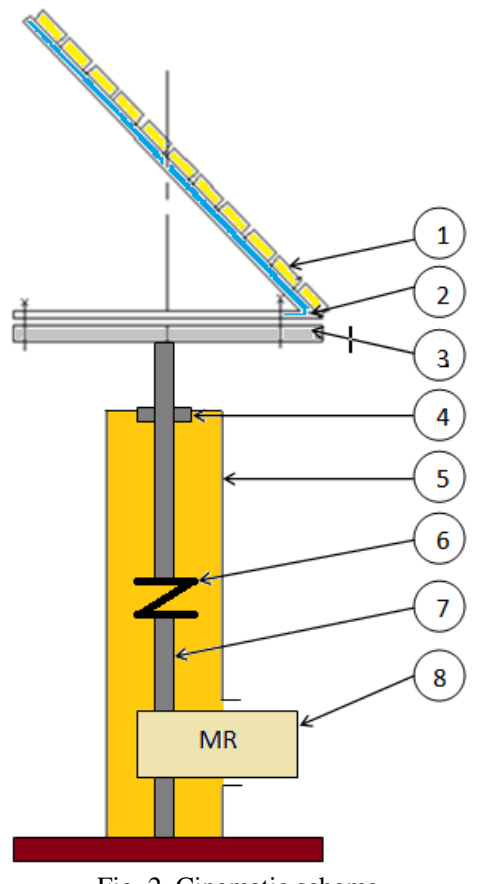

Fig. 2. Cinematic scheme

Assembly components are described below:

1. Photovoltaic

2. Support photovoltaic

3. Turntable

4. Roller bearing (thrust bearing)

5. Housing / frame

6. Flexible coupling

7. Tree

8. Motor-gearbox group

The formula for calculating the approximate azimuth angle is shown in equation (1), where: $\Phi_{\mathrm{S}}-$ azimuth angle; $\theta_{\mathrm{S}}-$ elevation angle; $\delta$ - declination of the sun; $\Phi$ - local latitude.

$$
\cos \Phi_{s}=\frac{\sin \delta-\sin \theta_{s} \sin \Phi}{\cos \theta_{s} \cos \Phi}
$$

Elevation angle is negative when the sun drops below the horizon. This angle may be approximated by the equation (2), where: $\mathrm{h}$ - hour angle; $\theta_{\mathrm{S}}$ - elevation angle; $\delta$ - declination of the sun; $\Phi$ - local latitude. [6]

$$
\sin \theta_{s}=\cos h \cos \delta \cos \Phi+\sin \delta \sin \Phi
$$

The hour angle of a point is the angle between two planes: one containing the Earth's axis and the zenith (the meridian plane), and the other containing the Earth's axis and the given point (the hour circle passing through the point). The angle may be expressed as negative east of the meridian plane and positive west of the meridian plane, or as positive westward from $0^{\circ}$ to $360^{\circ}$. The angle may be measured in degrees or in time, with $24 \mathrm{~h}=360^{\circ}$ exactly. For example for 10:30 AM, hour angle is -22.5 degrees (according to equation (3)).

$$
\mathrm{h}=(\text { Time}-12) * 15+\text { minutes } * 0.25
$$

The declination of the sun is the angle that the sun's rays make it with equatorial plane. This angle is shown in equation (4), where: $\mathrm{N}$ represents number the day from current year and is calculated according to the equation (5).

$$
\delta=23.44^{\circ} \sin \left[\frac{360^{\circ}}{365}(N+284)\right]
$$

$\mathrm{N}=\operatorname{int}(275 *$ month/9) $-2 *$ int $(($ month +9$) / 12)+$ day-30

The software was made in XILINX ISE and implements the algorithm for calculating the two angles of the sun shows two paintings:

- one for location data and is made up of several fields, for the following data: latitude, data from calendar (day / month / year) and local time in $24 \mathrm{~h}$ format, hour GMT +2 (hour / minute);

- and the second is for the results, and gives the calculated values of the declination angle, elevation, azimuth, azimuth east, sunrise in minutes and number of days of the year.

With this algorithm we can calculate the position of the sun for every day of the year with an good precision, so the voltage debited to photovoltaic panel to be high. Due to mechanical implementation of solar tracker, which can move on east-west direction up to 270 garde was able to simulate the longest day of the year which was on June 21 (the summer solstice).

\section{Xilinx ISE and Complex Programmable Logic Devices Board}

Software XILINX ISE (Integrated Software Environment) is the ideal solution for CPLD and FPGA design offering HDL synthesis and simulation, implementation, device fitting, and JTAG programming. To achieve an application can use schematic description or hardware description languages (VHDL or Verilog).

With this program can be achieved a synthesis applications, which means behavioral model transformation made in a hardware description language (VHDL or Verilog) in a circuit structure.

A complex programmable logic device (CPLD) is a programmable logic device with complexity between that of PALs and FPGAs, and architectural features of both. The main building block of the CPLD is a macrocell, which contains logic implementing disjunctive normal form expressions and more specialized logic operations. [6]

CPLDs have used analog sense amplifiers to boost the 
performance of their architectures. This performance boost came at the cost of very high current requirements. CoolRunner-II CPLDs, created by Xilinx, use an innovative all-digital core to achieve the same levels of performance at ultra-low power requirements. This allows designers to use the same CPLD architecture for both high-performance and low-power designs.

CoolRunner-II CPLDs are the latest CPLD product offering from Xilinx. CoolRunner-II CPLDs combine high performance with low power operation. Standby current on CoolRunner-II CPLD devices is less than $100 \mu \mathrm{A}$.

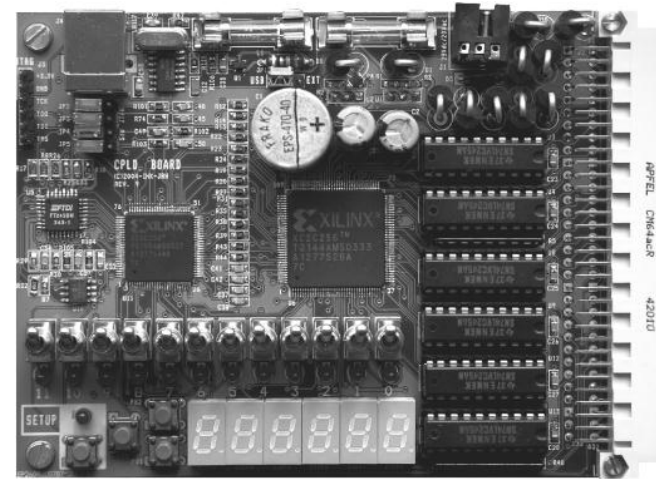

Fig. 3. CPLD board

\section{APPLICATION DESCRIPTION}

The program uses:

- a 10-bit input (std_logic_vector - up),

- a clock signal as input (std_logic - clk),

- a reset button (reset),

- an output of 6 bits (std_logic_vector -digit), which is used to select the display is lighted,

- six outputs 8-bit (std_logic_vector -segments) to display characters from ' 0 ' to ' 10 ' or ' 10 ' to ' 0 ',

- if the panel is moving then the motor is on "P" and if the panel not move then the motor is off "O"

- if the panel moves from east to west, ie from East to West, shows "ra" and backward "ar", or waiting in a certain position "PS".

The frequency is set manually on board CPLD to $1000 \mathrm{~Hz}$.

To display all values from ' 0 ' to ' 10 ', or ' 10 ' to ' 0 ', characters "ra", "ar", "PS", "O" and "P" are used:

\# a clock signal,

\# six displays "digit",

\# 8 bit output "segments" used for each segment of a

7-segment display,

\# 1 button "reset",

\# 10 switches "up".

The main modules of the application are shown in Figure 4.

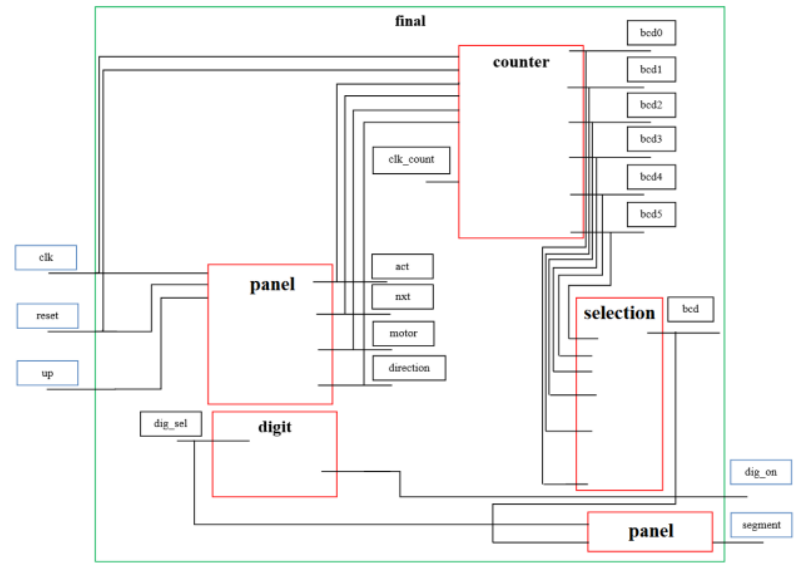

Fig. 4. The main modules of the application

The panel will have 10 positions and may submit the following states:

- waiting in a position for change the input, i.e. waiting for activation the sensor corresponding with the motor in position stop; the panel in mod initial is in position 1 , that position being standard position;

- the photovoltaic panel can move from East to West, given command with help of the ten switches, or from West to East, that move will be achieved without an intervention when the panel reached its final position;

- the 10 buttons on the CPLD board, will be used for "up".

- the 6 displays on the CPLD board, will be used:

$>2$ for position number $(0-10)$;

$>3$ for panel direction ( $\mathrm{ra}$ - moving from East to West, ar - moving from West to East, $P S$ when it is in a certain position pending);

$>1$ for motor status ( $P$ - on, $O$ - off).

\section{A. The Final Module}

In the final module, all sub-models are put together and it gives us actually used inputs and outputs board CPLD. The variable dig_sel is used as input for certain models, it is declared as signal and and the process that gives its values is:

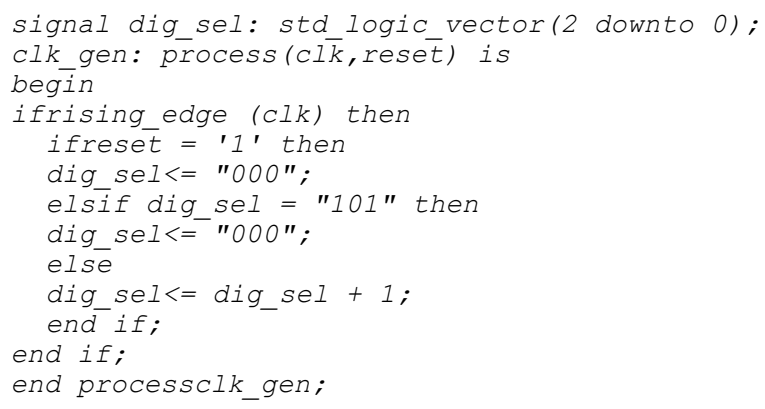

The functionality is described in the module architecture where the instruction to "portmap" is used in each sub-component model.

digitl: digit port map (dig_sel => dig_sel, dig_on => dig on); 


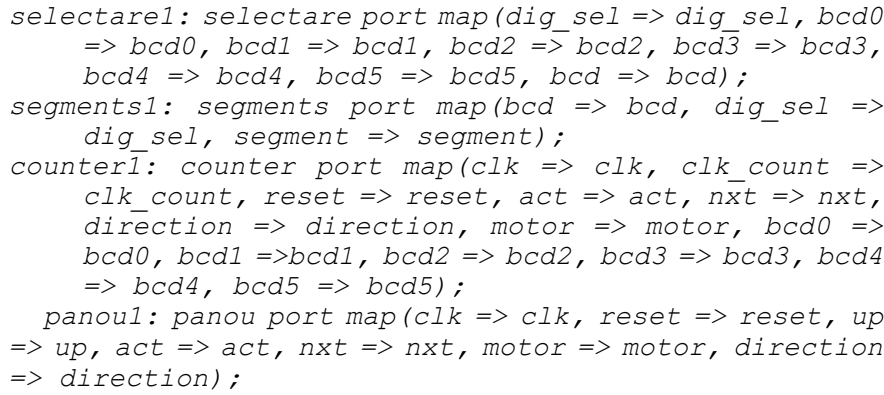

\section{B. Machine with Finitely Many States - Panel Module}

For description movement panel it is used a module what containing a finite state machine. This state machine will have 10 states to describe when the panel expects every position for something to happen or when it has reached the position applied for, nine states for situations where panel moves to a higher position and 9 states for cases where panel switch to inferior position (figure 5). The time required for the panel to move from one position to another signal is given by "tm", and the waiting time at a fixed position is "tm2". The position where the panel is at a time is given by variable called "act" and the next position, where it will arrive is called "nxt", these two are the results for this module. The inputs for this module is switches (up). If the reset button is pressed it does not matter if the panel is moving or pending, resumes the first position immediately.

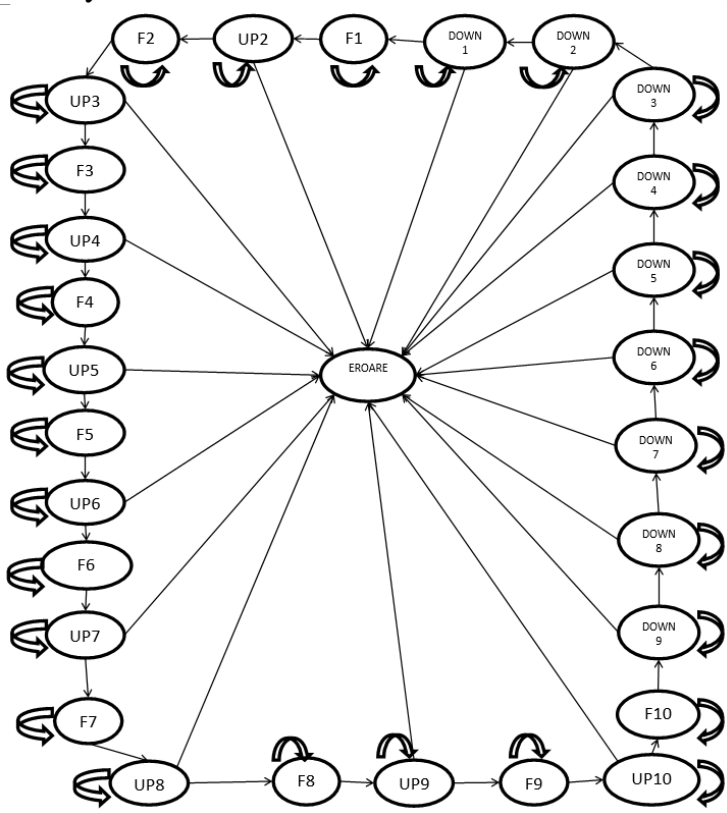

Fig. 5. The sequence motion states

Legend: F1, .., 10 - the steps of waiting in a given position; UP2, .., 10 - phases of transition from a lower position to a higher position; DOWN1, ..., 9 - phases of transition from a higher position into a lower position; ERROR - the step that activates a sensor wrong.

In Figure 6 are shown some states of the panel, and in Figure 7 are shown a few examples of transition states and change the values of the variables used in the program.
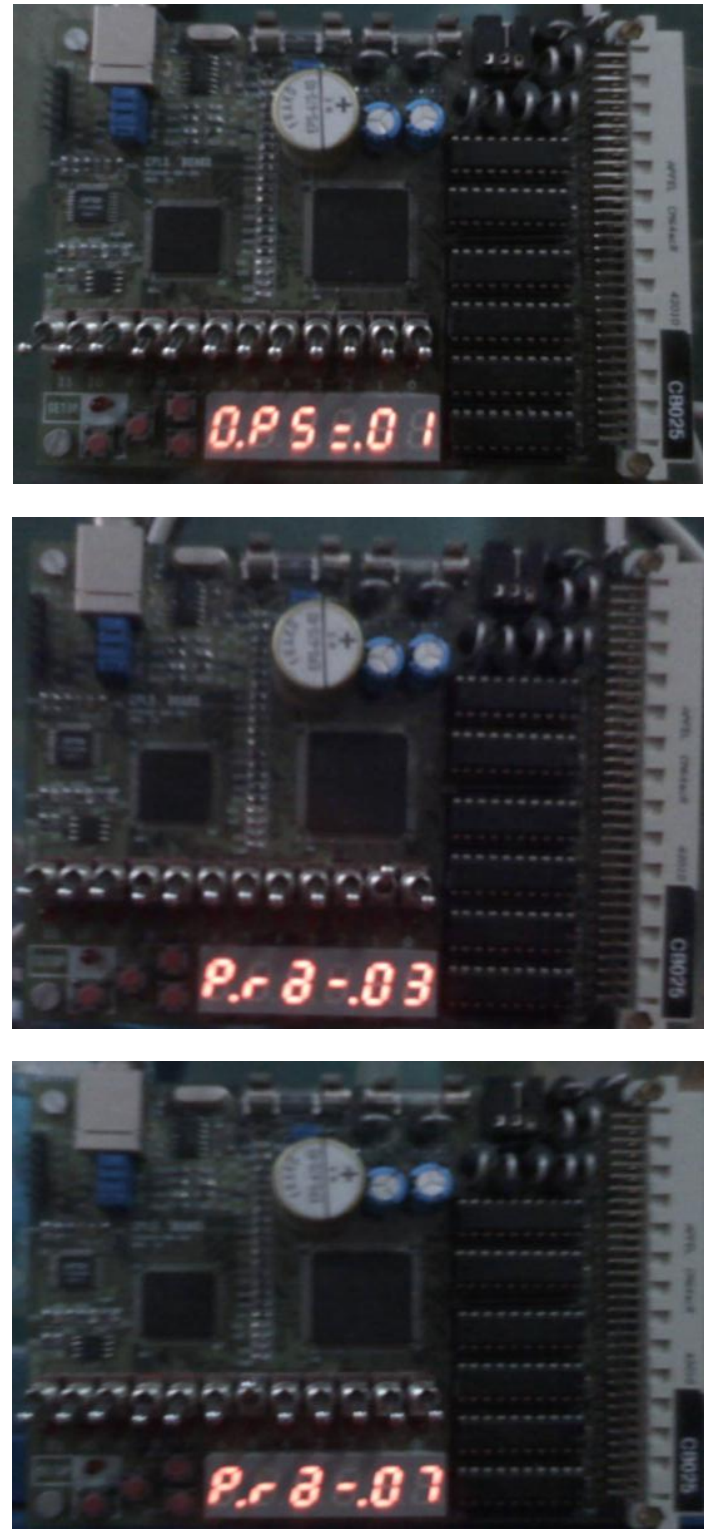

Fig. 6. Representing the first state, the movement to the second position and the state of recovery of the panel

\section{Counter and Selection Module}

Counter module has two 1-bit inputs (clk, reset), and two 4-bit inputs (note, nxt). Counting the positions is made with six signals called count 0 , count 1 , count 2 , count 3 , count 4 , count5. This is also used to give the screen the direction of movement and the motor condition. Six signals are used to retain values to the counter, because there are six display and values of these counters will be finally sent outputs bcd0, bcd1, bcd2, bCD3, bcd4, bcd5, which will represent a set of values entries into another way, namely selection. When one of the signals used for counter has the value "0000", the display will show 0 , "0001", it will display 1, "0010"-2, "0011"-3, "0100"-4, "0101"-5, "0110"-6, "0111"-7, "1000"-8, "1001"-9, "1010"-a, "1011"-r, "1100"-=, "1101"-P," 1110"- -.

The display will show, for example, when the panel is in the first position: O.PS-.01. If moving to the second position will appear: P.ra-.02. If moving down to the first position will appear: P.ar-.01. After the process is completed outputs (bcd0, 
bcd1, bcd2, bCD3, bcd4, bcd5) take values from signals count 0 , count 1 , count 2 , count 3 , count 4 , count5. (Figure 6)

After resolving the module of the counter, the next step is to make a new module called "selection" and it is used to determine which set of entries will be selected at any time, for each digit bcd0, bcd1, bcd2, bCD3, bcd4, bcd5. These are the inputs for this module plus an input dig_sel that helps us in selecting between these inputs. For example, if dig_sel is '000', then take exit bcd value bcd0. The selection module has six 4-bit input and a 3-bit input.
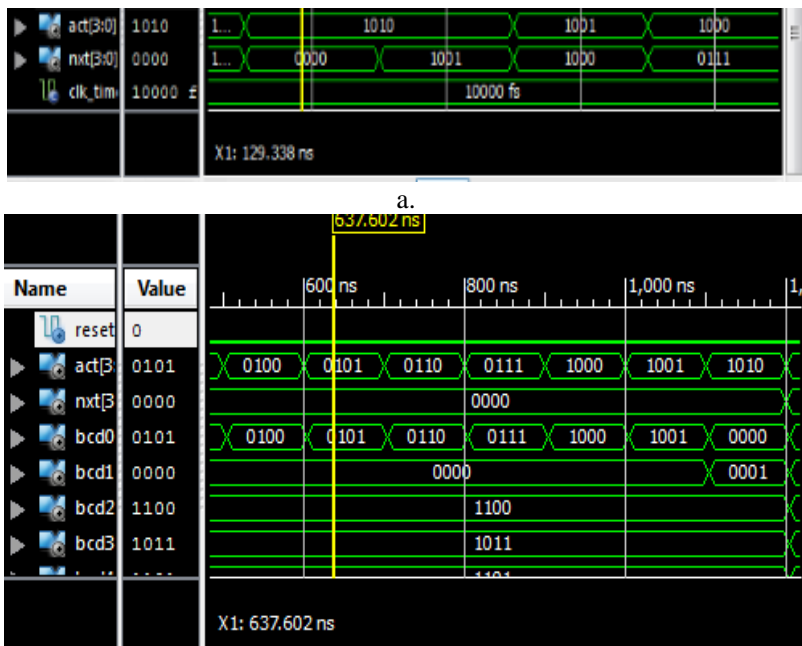

b.
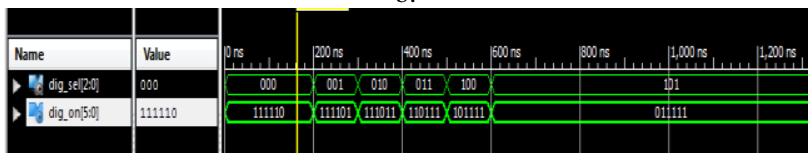

Fig. 7. a. transition states; b. change of values bcd; c. change the variable dig_on

\section{Digit and Segments Module}

To display the desired values use six displays with 7-segments. If desired to display status panel in a certain moment, all six displayed must be illuminated at the same time, and that means very quickly changed the digit that is active at a time. This is made using a clock divider implemented through a process in the main module. The purpose of this module is to get the impression that all visualization devices are illuminated simultaneously. A digit is active when set low 0 . The digit module has an input 3-bit.

To display the desired values use six 7-segment displays, a display of seven separate lights and one for light point. To display a number or a character set value segments vector must be translated into a combination of active outputs. For example, if $0000 \mathrm{BCD}$ input, the display will show 0 , ie segments $\mathrm{a}, \mathrm{b}, \mathrm{c}$, $\mathrm{d}$, e and $\mathrm{f}$ shall be illuminated to show the number 0 .

The segment module has a 4-bit input and a 3-bit. The input Dig_sel is used for choose the point when the light is on. Show can appear "0000" - 0, "0001" - 1, "0010" - 2, "0011" - 3, "0100" - 4, "0101" - 5, "0110" -6, "0111" - 7, "1000" - 8, "1001" - 9, "1010" - a, "1011" - r, "1100" - =, "1101" - P, "1110" - -, and if it appears another value will not light a segment.

\section{EXPERIMENTAL RESULTS}

In Figure 8 is shown experimental application "PV solar tracker" what describe the motion tracking the Sun trajectory.
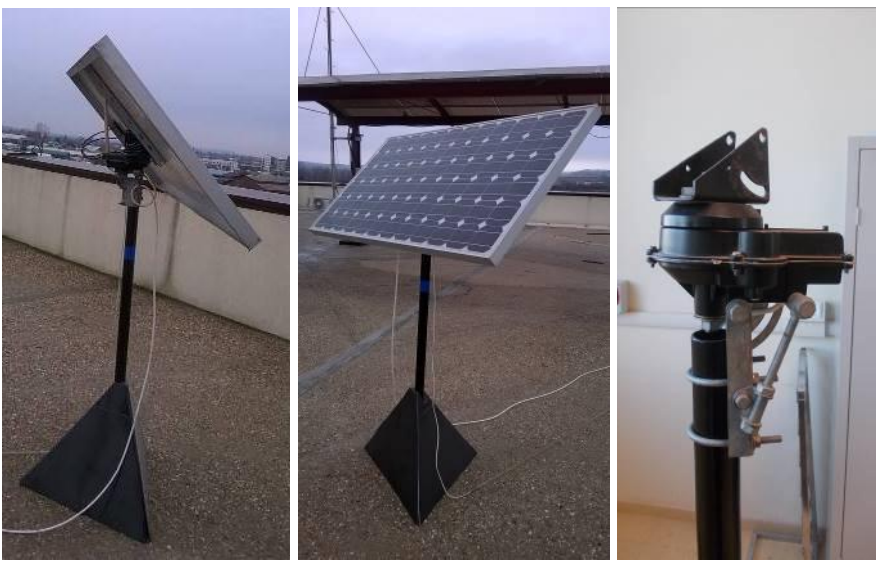

Fig. 8. PV solar tracker

In the Figure 9 we have represented the power $(\mathrm{P})$ debited of photovoltaic panel. Period the monitoring is in between the hours 07:05 and 17:35 in 14 December 2016.

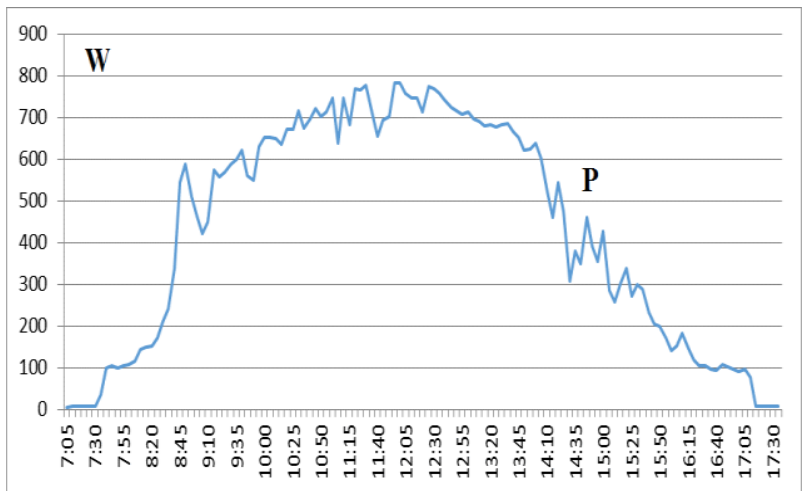

Fig. 9. Power obtained by acquisition from photovoltaic panel

\section{CONCLUSION}

The article solved an innovative problem related to solar energy capture systems and conversion into electricity. Permanent positioning of the solar panel after MPP point increases overall system efficiency. A photovoltaic tracker system is a solution one of those methods able to increase the PV power generation.

The objective of the program made in Xilinx IDE it was to describe the motion of a PV panel tracking the Sun trajectory. Thus, there was obtained a prototype of an algorithm for two-axis tracking PV panel, who follows the MPP using a CPLD board and Xilinx ISE software. Thus, PV panel will reach its MPP in relation date and time of the day.

The system will have an impact on the educational and research environment, being installed in the Multidisciplinary Science and Technology Research Institute of Valahia University of Targoviste and serving as teaching material for students of the Faculty of Electrical Engineering - Valahia University of Targoviste. 


\section{ACKNOWLEDGMENT}

This work was supported by a grant of the Romanian National Authority for Scientific Research, CNDI- UEFISCDI, project code PN-III-P2-2.1-BG-2016-0075.

\section{REFERENCES}

[1] World Energy Council, World Energy Resources, 2013 Survey, Ed. Regency House, London, ISBN: 978-0-946121-29-8, 2013

[2] Communication from the Commission to the European Parliament, the Council, the European Economic and Social Committee and the Committee of the Regions, Renewable Energy: a major player in the European energy market, http://eur-lex.europa.eu/LexUriServ/LexUriServ.do?uri= CELEX:52012DC0271:EN:NOT

[3] C.Y. Lee, P.C. Chou, C.M. Chiang, C.F. Lin, "Sun Tracking Systems: A Review", Sensors, Vol. 9(05), pp. 3875-3890, 2009, doi:10.3390/s90503875

[4] Woodbank Communications, Battery and Energy Technologies, Solar Power (Technology and Economics), http://www.mpoweruk.com/solar_power.htm, Retrieved 18.01.2016

[5] A. Oprea, F. Dragomir, "Positioning a PV panel on a rotary axis after maximum light", Scientific Bulletin of Electrical Engineering Faculty, Year 13, nr. 1 (21), Pages: 14-18, 2013

[6] F. Dragomir, S.St. Iliescu, Modelarea si simularea retelelor de joasa tensiune cu producere distribuita din surse regenerabile de energie, Ed. MatrixRom, Bucuresti, ISBN 978-606-25-0019-1, 2013

[7] Xilinx Inc., CPLD. What is a CPLD?, http://www.xilinx.com/cpld, Retrieved 11.12.2015

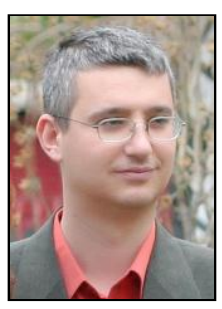

Florin Dragomir was born in Targoviste, at 25.04.1978, in 2002 obtained Engineering degree in the field of Automation and Industrial Informatics at Valahia University of Targoviste (Romania), and in 2009 obtained Doctorate's degree in the field of Automatics at Polytechnic University of Bucharest (Romania)

He has work experience as follows: 2003-2005 was Preparator, 2005-2011 was Assistant, 2011-2015 was Assistant Professor and from 2015 until now is Associate Professor to Automation, Computer Science and Electrical Engineering Department, Valahia University of Targoviste, Electrical Engineering, Electronics and Information Technology Faculty. Latest articles published are: (1) Dragomir O.E., Dragomir F., Stefan V., Minca E. Adaptive Neuro-Fuzzy Inference Systems as a Strategy for Predicting and Controling the Energy Produced from Renewable Sources, Energies, 8(11), pp. 13047-13061, 2015; (2) Dragomir F., Dragomir O.E. - Monitoring and diagnosis system based on fuzzy-multi agent tools, Proceedings of the 16th SGEM GeoConference on Energy and Clean Technologies, Albena, Bulgaria, 2016; (3) Dragomir O.E. , Dragomir F- Decision support system integrating fuzzy logic and expert system for optimization of smart grid functioning, Proceedings of International Conference on Control, Decision and Information Technologies (CoDIT 2016), 6-8 April 2016, ISBN: 978-1-5090-2189-5.

Dr. Dragomir is the Director of the project with code PN-III-P2-2.1-BG-2016-0075, and he led four projects as project manager, coauthored 9 books, 20 articles ISI and about 40 articles recognized IDB. According to Google Scholar database, the citation is 189 and Hirsch h-index 7

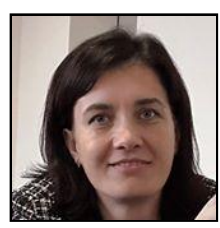

Otilia Elena Dragomir was born in Buzau, at 30.10.1977, in 2002 obtained Engineering degree in the field of Automation and Industrial Informatics at Valahia University of Targoviste (Romania), and in 2009 obtained PhD's degree in branch Automation from Universite Franche Comte de Besancon, France and Politehnica University of Bucharest, Romania. Her specialization is in field of control system and neural networks.

She has work experience as follows: 2003-2005 was Preparator, 2005-2011 was Assistant, 2011-2016 was Assistant Professor and from 2016 until now is Associate Professor to Automation, Computer Science and
Electrical Engineering Department, Valahia University of Targoviste, Electrical Engineering, Electronics and Information Technology Faculty. Latest articles published are: (1) Dragomir O.E., Dragomir F., Stefan V., Minca E. - Adaptive Neuro-Fuzzy Inference Systems as a Strategy for Predicting and Controling the Energy Produced from Renewable Sources, Energies, 8(11), pp. 13047-13061, 2015; (2) Dragomir O.E., Dragomir F., Development of user-friendly tool for energy behavioral change of consumers, The Scientific Buletin of Electrical Engineering Faculty, no.1, 2016, ISSN 2286-2455; (3) Dragomir O.E. , Dragomir F- Decision support system integrating fuzzy logic and expert system for optimization of smart grid functioning, Proceedings of International Conference on Control, Decision and Information Technologies (CoDIT 2016), 6-8 April 2016.

Dr. Dragomir is coauthored a 10 books, 22 articles ISI and about 45 articles recognized IDB. According to Google Scholar database, the citation is 229 and Hirsch h-index 6.

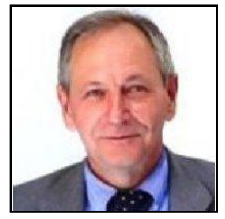

Nicolae Olariu was born at 17.04.1954, in 1979 obtained Engineering degree in the field of Electrotehnics at Politehnica University of Bucharest, Romania, and in 1996 obtained $P h D$ 's degree in branch Electrotehnics from Politehnica University of Bucharest, Romania. Her specialization is in Electrical circuits theory, PV cells and modules, Distributed energy and Integration of PV systems in buildings.

He has work experience as follows: 1979-1993 was research to Research and Development in Electrical Engineering (ICPE) from Bucharest and from 1993 until now is Professor to Automation, Computer Science and Electrical Engineering Department, Valahia University of Targoviste, Electrical Engineering, Electronics and Information Technology Faculty. He has from 1993 until now the manager at Energy-enviroment Department, Valahia University of Targoviste, Multidisciplinary Science and Technology Research Institute. Latest articles published are: (1) Stanescu I.A., Stefan A., Stefan D., Dragomir F., Olariu N., Dragomir O.E. - Intelligent decision support for Renewable Energy Providers, Proc. of the 2014 International Conference on Control, Decision and Information Technologies (CoDIT2014), Page(s): 488 - 492, 2014.; (2) Dragomir F., Dragomir O.E., Olariu N., Oprea A. - Solution based on artificial intelligence in Smart Grid, Proceedings of the 28th European Photovoltaic Solar Energy Conference and Exhibition (EU PVSEC 2013), 30 Sep - 04 Oct 2013, Pages: 3888-3891, Paris, France; (3) Dragomir F., Dragomir O.E., Olariu N., Minca E. - Control Solution Based on Fuzzy Logic for Low Voltage Electrical Networks with Distributed Power from Renewable Resources, Proceedings of the 25th European Photovoltaic Solar Energy Conference and Exhibition (25th EU PVSEC), pg: 4988 - 4991, 06-10 September 2010, Valencia, Spain.

Prof. Olariu led 23 projects as project manager, coauthored 7 books and more 100 articles and participation at conferences national and international. $\mathrm{He}$ is a member of EU PV Technological Platform, association ENERO, association SunE, etc.

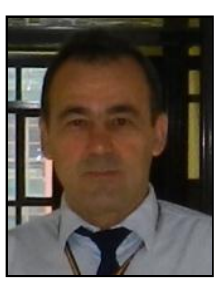

Adrian Oprea was born at 13.11.1963, in 2001 obtained Engineering degree in the field of Automation and Industrial Informatics at Valahia University of Targoviste (Romania). Her specialization is in PV cells and modules and Distributed energy.

He has work experience as follows: 1986-1997 was subingineer to Mechanical Enterprise from Mija, Romania and from 1997 until now is subingineer and ingineer to Valahia University of Targoviste. He has from 2006 until now is ingineer at Energy-enviroment Department, from Multidisciplinary Science and Technology Research Institute. Latest articles published are: (1) Oprea A., Dragomir F., Dragomir O.E., Olariu N., Olteanu L. - Monitoring of Electrical Parameters into Island Grid Integrating Renewable Energy Sources, Applied Mechanics and Materials, Volumes 368 - 370, Pages: 346-349, 2013; (2) Dragomir F., Dragomir O.E., Oprea A. Stand-Alone Power System for Monitoring and Control of the Temperature, Advances in Energy Science and Technology, PTS 1-4, Book Series: Applied Mechanics and Materials, Volume: 291-294 Pages: 2570-2573, 2013; (3) Oprea A., Dragomir F. - Positioning a PV panel on a rotary axis after maximum light, Scientific Bulletin of Electrical Engineering Faculty, Year 13, nr. 1 (21), Pages: 14-18, 2013

Mr. Oprea has from 2013 until now PhD student in the field Renewable Energy Sources, and is coauthored for more 20 articles and participation at conferences national and international. 